UC-20

Reporting Date: December 1975 Issued: December 1975

\title{
Design of the ZT-1 Toroidal Pinch Experiment
}

\author{
by
}

D. A. Baker

L. C. Burkhardt

R. S. Dike

J. N. Di Marco

P. R. Forman

A. Haberstich

H. J. Karr

L. W. Mann

J. A. Phillips*

A. E. Schofield

"Director of Physics Division, International Atomic Energy Agency, Headquarters, Vienna, Austria.

LOS ALAMOS. NEW MEXICO 87545

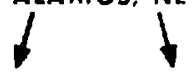

An Affirmolive Action/Equal Opportunity Employer 
In the interest of prompt distribution, this report was not edited by the Technical Information staff.

Primled in the IInited States of America. Available from National Technical Information Service

II.S. Depart ment of Commerce

5ens Wurt Resval Rinad

Price: Printed (')w \$4.50) Microfiche \$2.25

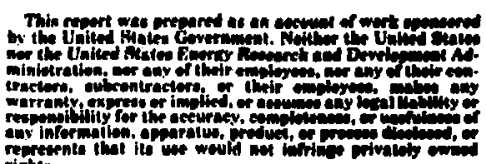

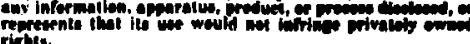


DESIGN OF THE ZT-1 TOROIDAL PINCH EXPERIMENT

by

D. A. Baker, L. C. Burkhardt, R. S. Dike, J. N. DI Marco, P. R. Forman,

A. Haberst1ch, H. J. Karr, L. W. Mann, J. A. Phillips, and A. E. Schofleld

\section{ABSTRACT}

Electrical design detalls are given for a toroldal z-pinch device named ZT-1 that uses field programing to achieve a stable, reversed field pinch. The plasma is formed in a 4-mm-thick, 10.3-cm-1.d., high-alumina, segmented ceramic vacuum chamber. Voltages as high as $70 \mathrm{kV}$ are routinely attalned by interrupting with a fuse $800 \mathrm{kA}$ in an inductive store. The current is diverted from the fuse to the primary of a single-turn transformer divided into quadrants. A total of $280 \mathrm{kV}$ at $200 \mathrm{kA}$ can then be applied to the plasma, which forms the sesondary circuit of the transformer. Th1s system produees $\mathrm{dB} / \mathrm{dt}^{\prime} \mathrm{s}$ of up to $8 \mathrm{~T} / \mathrm{us}$; wh modifications to the electrical system, $\mathrm{dE} / \mathrm{dt}^{\prime} \mathrm{s}$ as low as $0.1 \mathrm{~T} / \mathrm{s}$ are obtatned. The $B_{2}$ blas fleld of up to $0.25 \mathrm{~T}$ can be reversed at a rate of up to 0.2 T/us. Both $B_{\text {and }}$ a magnetic fleld errors are minimized. The design of the fuses and magnetic core and the development of a low inductance and resistance metal-to-metal crowbar are described.

\section{INTKODLITLON}

Although the early z-pinch results were characterized by short, stable lifetimes and lon temperatures of $₹ 100 \mathrm{eV}$, several recent experitnents have obtained gigniflcantly longer stable times and higher temperatures. Ohkawa et al, obtained Improved performance in a toroldal z-pinch experiment by programing inagnetic flelds and reducting nagnetic fleld errors. Kobinson and $\mathrm{King}^{2}$ report a prolonged stable pertod 1 imited by classical diffusion of flelds for a diffuse 2 pinch. Bobeldijk et $a 1^{3}$ and Wilhelm and $Z_{w 1 c k e r}{ }^{4}$ report 11 fetimes up to $20 \mu \mathrm{s}$, also IImited by field diffuston, and temperatures up to $1000 \mathrm{eV}$ for screw-pinch experiments. DI Marco and Burkhardt ${ }^{5}$ have obtatned ton temperatures of $\sim 500 \mathrm{eV}$ and contalnment times of $\sim 10 \mathrm{us}$ limited by end effects in a linear $z$ pinch.

Numerical calculations of implosion heating ${ }^{6}$ predict plasma temperatures of several $\mathrm{keV}$ for both $\theta$ and $z$ pinches for comparable starting conditions using field magnitudes readily avadlable in the laboratury. However, in past experiments, 2 pinches have not attained temperatures as high as those observed with the $\theta$ pinch. This can be attributed to differences in starting conditions. An important parameter in the implosion-heating process is the Initial rate of rise of the magnetic "piston" drivIng the plasma." Using the snowplow model, it can he shown ${ }^{\theta}$ that the initial acceleration is proportional to $(\mathrm{dB} / \mathrm{dt}) / \sqrt{\mathrm{p}}$ where $\mathrm{dB} / \mathrm{dt}$ is the rate of change of magnetic field at the plagma surface and $\rho$ is the initial plasma density. Compared to the $\theta$ pinches, past $z$-pinch experiments did not achleve comparabIe $\$ / \sigma$ with two exceptions. The firat ${ }^{9}$ employed a discharge volume $1 \mathrm{~cm}$ In diameter and $2 \mathrm{~cm}$ long, limiting diagnostics severely. The second 10 experlenced secondary wall breakdown after pinch formation.

The 2T-1 toroidal $L$-pinch experiment employs a magnetic energy storage system and fuse switching to extend the range of the z-pinch experiment. This affords a high-voltage source capable of supplying current at a rate of $22 \times 10^{12} \mathrm{~A} / \mathrm{s}$ with peak discharge voltages of $\imath 70 \mathrm{kV}$ per torus quadrant and 
peak currents of $\gtrsim 200 \mathrm{kA}$. With these short current and voltage risetimes, the value of $\dot{B} / \rho$ exceeds those attained with present $\theta$ pinches. The voltage rises to Its peak value in $\sim 0.3 \mu \mathrm{s}$, then falls to a low value in $\lesssim 2 \mu$ s to avold secondary wall breakdown problems.

In this report, the design and operation of the ZT-1 system are described. The torus assembly and the magnetic energy storage system are discussed in Sec. II and the field programing and assoclated electronic circuitry in Sec. III. In Sec. IV, the theory of the fuse switching and inductive storage behavior is reviewed with results of the analog fleld and current flow mapping used in the system design. The measures taken for correction of magnetic field errors are given in Sec. $V$. The tron core design and testing procedure are described in Sec. VI. Spark gap and crowbar test results are given in Sec. VII.

\section{TORUS ASSEMBLY AND MAGNETIC ENERGY STORAGE} SYSTEM

Figures 1 and 2 are isometric sectional drawIngs of the $2 T-1$ system. The requirement of very high current rise $\left(\sim 2 \times 10^{12} \mathrm{~A} / \mathrm{s}\right)$ for the implosion heating has been attained by high-voltage, lowInductance design and a unique magnetic energy storage and fuse switching system. The toroidal discharge tube is located within a large coaxial "barrel" $244 \mathrm{~cm}$ in diameter and $90 \mathrm{~cm}$ high. The barrel is made from $1.87-\mathrm{cm}-\mathrm{th}$ tck aluminum with reinforcing $r$ tbs to withstand the large magnetic forces. There is $0.15-c m$ total thickness of layered mylar Insula$t$ ton between the coaxlal cylinders of the barrel. This insulation has been tested conservatively at $\sim 100 \mathrm{kV}$. The function of the barrel is to act as a magnetic energy storage inductor symetrically connected to the coaxial cables from the capacitor bank at the bottom end, and also symmetrically connected to the four fuses and parallel-plate cransmission lines to the torus at the upper end. The storage inductor is formed near the bottom of the barrel by reducing the radius of the inner coaxial conductor over an axicl length of $\approx 50 \mathrm{~cm}$. An array of vertical bars, shown in Fig. 1, forms the inner conductor of this section and is moveable to allow the radius and, thereby, the storage inductance to be varled from 5 to $40 \mathrm{nll}$.
The top of the barrel is contoured to connect with the four tapered parallel-plate transmission 11nes. There lines connect in turn to the four fuses, transfer switches, and the four feedpoints of the torug primary. When the capacitor bank spark gap switches (see Sec. III) are tr1ggered, current flows through the barrel, a section of the parallel plate lines, and the four fuses. As the current rises, magnet 1 : energy 18 stored in the inductor. After $\sim 7 \mu \mathrm{B}$, the resistance of the fuses increases by a factor of $\sim 100$ as they vaporize, and, due to the circuit inductanie, voltages $\sim 5$ times the bank voltage are developed across the fuses. The rise In voltage causes the transfer spark gap switches to fire transferring the voltage and current to the. torus. The voltage acring each fuse drives onequarter section of the toroidal discharge. A voltage as high as $80 \mathrm{kV}$ per quadrant can be developed with the present system. However, to avoid possible Insulation breakdown, 60 to $70 \mathrm{kV}$ have been chosen. This tecinique affords very rapid transfer of current to the pinch discharge because of the high voltage and low load inductance. A more detailed and quantitative analysis of the magnetic energy storage and fuse switching circuit behavior is given in Sec. IV.

Simultaneous operation of the fuses and transfer switches in the four quadrants is essential to produce the same voltage and current characteristics at the four feedpoints in the torus. In the event of mismatch in fuse operation, current from adjacent fuses will be diverted to the one having lower voltage because of the coupling between fuses by the contoured sections of the barrel. Questions of simultaneity and fitcer are considered in more detail In Sec. IV.

The torus primary, lso shown in Fig. 1, is made of $1.27-\mathrm{cm}$ wall thickness, $11.6-\mathrm{cm}$ bore, alum minum. The mean major diameter is $76 \mathrm{~cm}$. This primary is assembled in four sections and is split in this meridian plane for ease of assembly and to provide an Insulated gap around the inner ajor c1rcumference. This inner gap allows rapid penetration of the toroldal magnetic field itito the torus. There is a toroldal winding of 66 turns of 18 wire around each quadrant of the aluminum primary with the cur rent return through the primary to minimize fleld errors. The maximum $\dot{B}_{z}$ is obtained wi:h two 


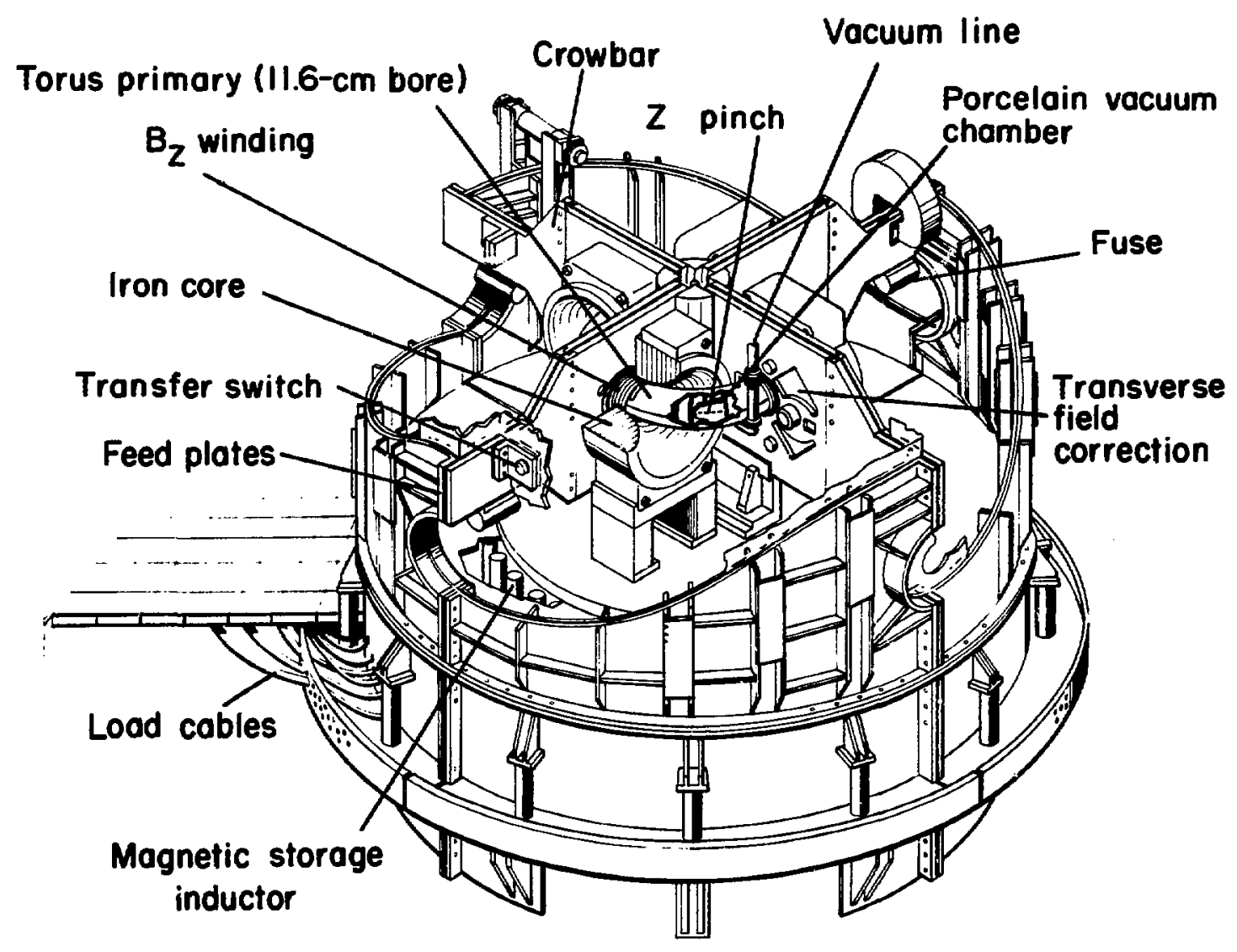

F18. 1. Partially cut away drawing of the 2T-1 device.

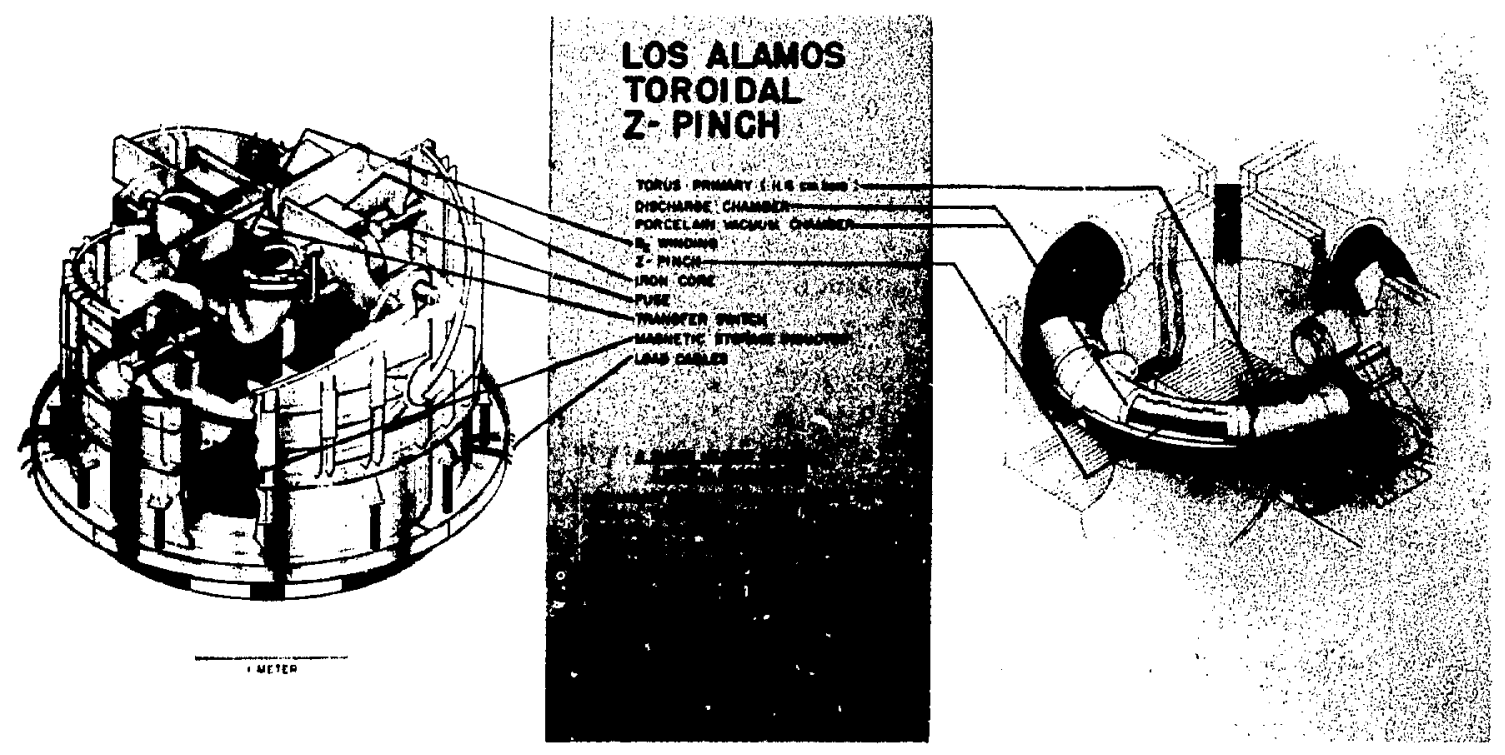

F1g. 2. Partially cut away drawings of the ZT-I device. 
32-turn coils per quadrant; again all drives are in parallel.

Since the primary is connected at four feedpoints to the parallel plate transmission lines, the four primary sections are electrically in parallel; the secondaries, or plasma discharge, are in series. The paralle1 plate lines at the feedpoints are 0.76 m wide with 1.2-mm insulation thickness to provide low inductance. Because the current flow along these lines is transverse to the torus, magnetic ftelds transverse to the discharge result unless the current flow pattern is controlled and forced to have the same azimuthal distribution, 1deally, as tho plasma image current inside the primary. This is accomplished by inductive cut out sections in the transmission lines as shown in Fig. 1. In addition, split copper cylinders are inserted inside the priwary at each feedpoint to divert the residuni transverse field. These field correction devices and the related test measurements are discussed in more dotall In Sec. V. Also, analysis of fleld perturbations introduced by the pump port tubulations is given in Sec. $V$.

The vacuum chamber inside the primary is formed from ninety 10.3-cm-1.d., 4-mun wall thickness ceramic ( $99.8 \%$ purtty vitrifted $\mathrm{Al}_{2} \mathrm{O}_{3}$ ) sectors.

The ceramic pieces were ground and tapered to fora $4^{\circ}$ sectors for the torus. Overlapping step jolnts are provided at the edges of the sectors with a gap at the outer edges for insertion and seating of Viton O-rings. Under vacuum, the o-rings compress by $\sim 0.5 \mathrm{am}$ and form a reliable seal. This compression causes the inner lip of the ceramic step joint to close. The $0 \rightarrow r i n g$ at the other end of the joint Is shlelded from the plasma discharge. Quartz window inserts provide viewing ports for diagnosties in two sectors. Two 1.2-cm-1.d. pump-out tubes are provided at the tup and bottom of one sector in eacti quadrant of the assembly. These connect through flextble bellows to the vacuum manifold. Vacuum of: $3 \times 10^{-6}$ Torr is obtained with this system using a $260 \mathrm{l} / \mathrm{s}$ turbomolecular vacuum pump in parallel with a $500 \mathrm{\ell} / \mathrm{s}$ Vacion pump.

close spacing tolerances are naintalned to minimize inductance. The total gap between the $0 . d$. of the cramic and the i.d. oi the primary, including $0-r i n g$ extension and insulation, is $\eta 2.5 \mathrm{~mm}$.
A laminated magnet ic core is inserted in each quadrant to lmprove the coupling efficiency of the primary circuit to the discharge. With the magnetic core, the magnetization current in the pritury circuit is reduced by more than two orders of magnitude so that primary current has nearly the sime value as the current in the plasma discharge. Also, with the reduced magnetization current flowing on the outside of the primary, the problem of fleld errors (sec sect. v) Introduced by this current component becomes minimal and only the image current correction need be considered. The core design is discissed in Sec. vi.

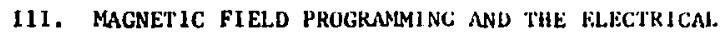
SYSTEM

A. Stable Fleld Configurations and Programed Field Stabilization

MHD theory shows that there are stable diffuse z-pinch configurations capable of plasmas of high $B_{\theta}$ 's( $\left.\sim 0.5\right)$. The specific stability conditions that must be met, are described in the literature. $11-14$ The magnetic field and plasma pressure distributions shown In Flg. 3 form a typical stable configuration. To reproduce such a theoretical configuration in the experiment, the fleld progranming sequence fllustrated in Fig. 4 is followed. The radial behavior of the flelds during the discharge is shown at the top of the flgure. Thi center two curves show the $t_{i}$ and $I_{z}$ current wave forms. At the botton of the figure, the magnetic field and plasma pressure profiles are shown at selected times in the discharge. The third

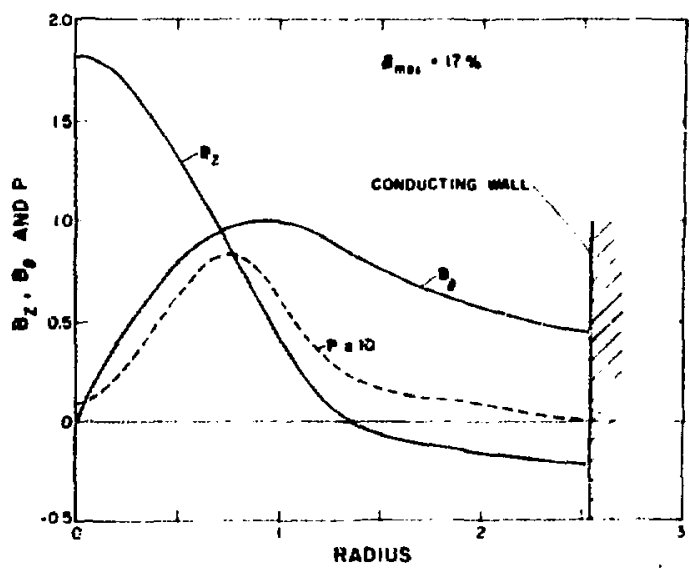

F1g. 3. Examples of magnet fc field components and plasma pressure, as a function of radius for stable pinch configuration in $21-1$. 


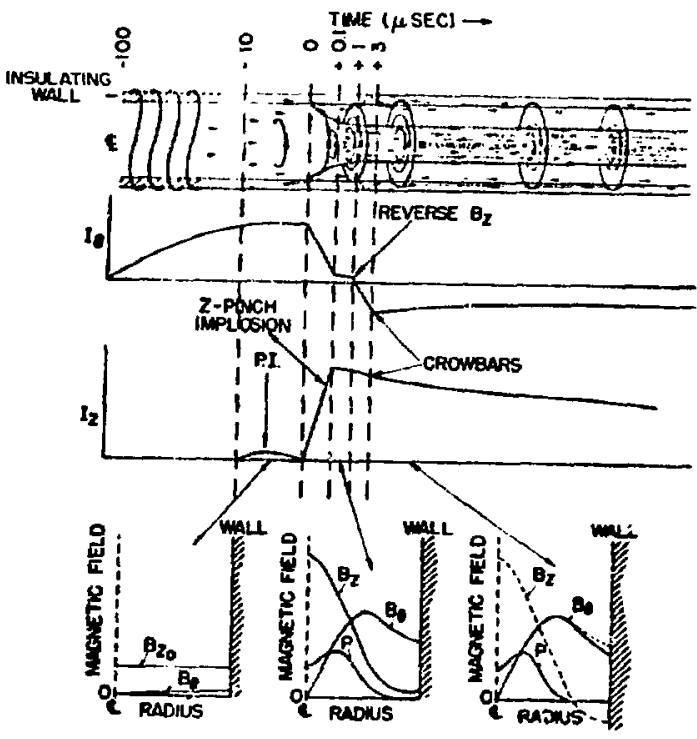

ig. f. Schematic summary of the magnetic field programming sequence required in $\mathrm{ZT}-\mathrm{l}$.

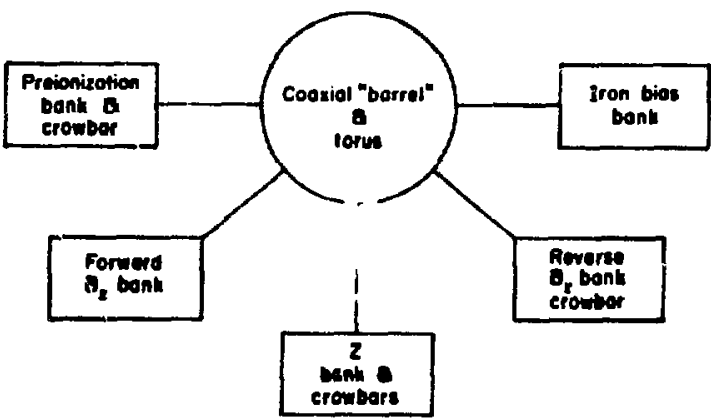

Fig. 5. Block diagram of the energy stores associated with the $27-1$ device, namely the profonlzat ion bank and its crowbar. which takes the plasma from a feeble $r f$ glow to a plasma about $100 \%$ tonized; the in ron bias bank, which returns the itron to a starting condition allowing the maximum yolt-second flux change of the iron: the 2 bank and its crowbars, which sets up the main flow of current in the plasma torus; the forward $B_{z}$ hank, which sets up the blas magnet fo field along the malor axis of the torus: and the reverse $B_{z}$ bank, which can be $t$ imed with respece to the 7 , bank. proflle should duplicate a theoretically stable configuration 1ike that in Fig. 3, with the distributions controlled by the timing and magnitudes of the toroidal $B_{z}$ fleld, reverse $B_{z}$ ffeld, plasma current, plasna pressure, and the crowbars which hold or linit the magnitudes at appropria:e values.

At $\sim 100$ us before the main z-pinch current is Initiated, $a B_{z}$ stabilizing field is turned on. About $\sim 20 \mu \mathrm{s}$ before the main 2 pinch, a $\lesssim 15-\mathrm{kA}$ preionization $z$ current is passed through the filling gas. The main t-pinch implosion then compresses the plasma and $B_{z}$ bias field about the axis, heating the plasma. At selected times the $I_{G}$ in the external winding is made negative by reversing the voltage across the coll. This produces a reversed $B_{2}$ field outside the pinch column. Finally, at $23 \mathrm{is}$, the $I_{\theta}$ and $I_{z}$ currents are crowbarred. The electrical system, shown in the biock diagram in Fig. 5, comprises five capacitor banks and four crowbar devices used in initiaing and rapid programing of the discharge.

\section{B. B Circuit}

The circult for producing the toroldal stabilizIng magnetic fields is shown in Fig. 6. This circult is designed to provide the inftial forward $B_{z}$ field then reverse the field outside the plasma after the pinch is intliated. In the circuit diagram, the capacitor bank at the left, comprising $c_{1}$, $i_{2}$, and $C_{3}$, is set up as a three-stago Marx circult with ignitron swteching. This part of the circuit generates the initial bias or forward $B_{z}$. The effective bank capacitance is $160 \mathrm{\mu F}$ with a maximum energy rating of $\sim 72 \mathrm{~kJ}$ and a maximum current of $\sim 20 \mathrm{kA}$ inco the load. At maximum cerrent, $5 \mathrm{kA}$ per

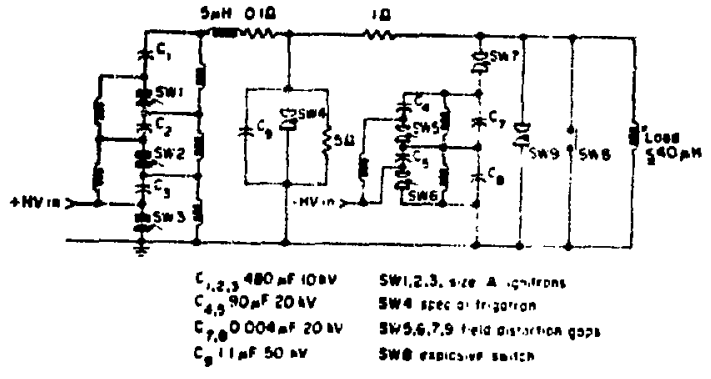

Fig. 6. Schematic electrical diagram of the $B_{2}$ system used in $a-1$. 
quadrant, a toroidal field of $26 \mathrm{kG}$ is produced at the axis of the torus. The forward $B_{z}$ current is more than eritically damped and reaches peak in about 60 us.

The $B_{\varepsilon}$ winding has two varlations depending upon the specified tagnitude and rate of change of the magnetic field. To obtain the maximum magnitude of forward and reverse $B_{2}$, a 66-turn coll of it 8 wire is placed around each quadrant of the torus and all four coils ari then electrically connected in parallel.

The rate of change of reverse $B_{z}$ is increased by a factor of two with two 32-turn colls of \#8 wire around each quadrant. All elght colls are then electrically connected in parallel.

Referring to Fig. 6, the 5- $-\mathrm{H}$ and $0.1-\Omega$ circuit elements are cable Inductance and resistance, respectively, and are inserted to $1 \mathrm{fmit}$ the current supplied by the forward Marx when the crowbar, Sw4, ts fired. $C_{1}$ and the $5-\Omega$ resistor are provided to roll over the leading edpe of the voltage waveform supplied from the forward Marx and prevent cable dowhling whlch overstresses swh and causes prefire protlems.

The reverse $B$, circuit is a two-stiage Marx circult with spark gap switches SwS, Swh, and Sw7. The effecture bank capactance is 245 iff with a maximum rated energy of $36 \mathrm{~kJ}$ and a maximum current of $225 \mathrm{kA}$ into the $B_{2}$ windings. The risetime of the reverise field is is 30 us and the maxinum $\mathrm{dB}_{2} / \mathrm{dt} \sim 0.1 \mathrm{~T} / \mathrm{us}$ in a vacuut. The field distortion spark gap, Sw9, and the explosive swltei, Sw8, serve as alternative methods of crowbarring the $B_{z}$ sustem.

In the nrogrammed firting sequence of the $B_{2}$ system, the forward $B_{2}$ system is fired, Swl, Sw2, and Sw3 followed, at " peak $B_{2}$ field, by the first crowbar, Sw4. The pinch current 1 is fired 20.5 ws after Swh and the reverse $B_{z}$ system is fired " 1 us before or after $I_{z}$. Finally the second crowbar, Sw8 or Sw9, is fired a few us following the reverse $B_{z}$ system.

\section{c. Fagnetic Core Back-Bias Circuit}

The plasma current, $I_{z}$, is coupled to the primary current by nickal-lron magnetic cores; we use the cetms "iron rcres" and "Iron" synonymously. The maximum core cross section that can be accommodated in each quadrant its $20.0425 \mathrm{~m}^{2}$. The cores are designed to accept a $\dot{B}$ of $3 \times 10^{10} \mathrm{G} / \mathrm{s}$. or $300 \mathrm{v} / \mathrm{cm}^{2}$, therefore requiring substant lal Insulation between both core laminations and groups of laminations. Because of the insulation requirements, a stacking factor of $\sim 0.70$ is achieved (or equivalent to about $300 \mathrm{sq} \mathrm{cm}$ of iron) with a vo:t-second rating of $24.4 \times 10^{-2}$. To use the iron avallable most effectively, the cores can be back-blased to saturation in the negative direction thus using the volt-seconds from negative to positive saturation (2 $8.8 \times 10^{-2} \mathrm{Vs}$ ), a factor of two gatn.

The circuit ased for back biasing the iron is very simple. Fig. 7, consisting of a capacitor $c_{1}$. and four separate inductors $L_{1}, L_{2}, L_{3}$, and $L_{4}$, each in series with a loop around one core $\mathrm{CR}_{1}, \mathrm{CR}_{2}, \mathrm{Cr}_{3}$, $\mathrm{CR}_{4}$. The inductance of a loop around a core is 280 wh, thas the serleg inductors deterwine the current value to first order. The clrcult provides for drives of 0 to $\checkmark 900 \mathrm{~A} / \mathrm{m}$, which allows setting the reverse bias from 0 to well past saturation. The period of the blas circuit is $22.3 \times 10^{-3} \mathrm{~s}$. The large value of serles inductance provides a very high inpedance to the prelonization and maln $\%$ currents which are coupled to the blas circult by the cores. The large inductance also allows only ح $400 v$ max to bo applited to the gas in the torusmnot sufficiont for iontzation.

D. Prelonizat ion Circuit

The preionization circuit, Fig. 8 , is composed of a "pre-preionizat lon" circult $\left(C_{2}\right.$, Sw4, and $\left.R_{2}\right)$

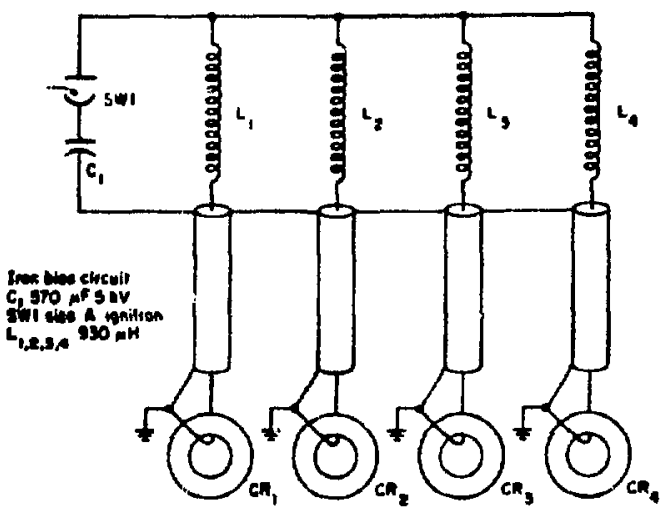

Fig. 7. Schematic electrical diagram of the tron hlasing circuie in $2 T-1$. 


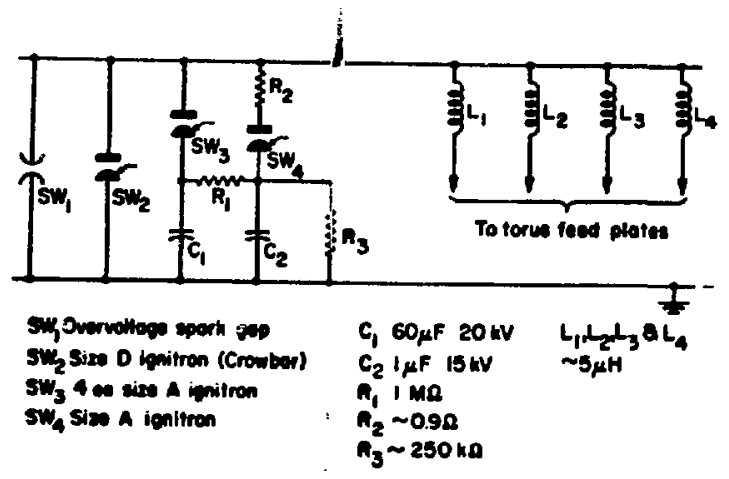

F18. 8. Schenatic eleistical diagram of the pretontzation capacitor discharge circuit.

In aeries with the fee, Inductance's $L_{1}, L_{2}, L_{3}$, $L_{4}$, and the torus. Th1s circult, like the aln preIonization circuit, provides $\sim 5 \mathrm{kV}$ wax to each quadrant to Initiate lonization. The circuit is heavily damped and has an RC decay of $\sim 1$ Hs. Its purpose is to initiste breakdown of the gas. Withcut this low-voltage bank the Inherent delay in the gas breakdown of $\sim 1$ He would result in the total voltage of the prelonization bank being developed at the torus. Under some conditions of operation this high voltage would cause the awitches in the min $I_{2}$ bank to fire.

The main pretonization bank $C_{1}$, and $5 w 3$, charged up to $\sim 15 \mathrm{kV}$, supplies sufficient energy to Ionize the gas completely. The voltage divides between the torus Inductance and the feed inductances, $L_{1}, L_{2}, L_{3}$, and $L_{4}$. The aximum current $1 \mathrm{~s} \sim 20 \mathrm{kA}$ per quadrant, with a period of ح 55 $\mu$.

The Inductances $L_{2}, L_{2}, L_{3}$, and $L_{4}$ Include the coaxial cable from the preionization bank to the achine and the feed ayatem Inductance at the machine. This rather large inductance prevents excessive current from flowing into the preionization syatem from the 2 bank when it is fired. Swl is a anple overvoltage sap set to break down at $220 \mathrm{kV}$ to protect the preionization componenta if the 2 bunk prefires. Sw2 allows the systen to be crowbarred from the start of preionization current up to about peak current.

As a general aid in breaking down the gas, an If generator at $\sim 29$ ahz 1 s coupled into one quadrant at the punp-out ports by an electrode inside a vacuun punp-out port.

\section{E. $\mathbf{I}_{2}$ Circuit}

The $I_{z}$ circuit provided the primary current to the aluinum torus. The Iron cores, Sec. VI, provide essentially unity coupling between priagry and secondary. The difference current during the very fast risetine of the plane current in the fuse node 1s only $\sim 1.5 \%$ of the priancy current.

The $I_{z}$ capacitor bank is a two-stage inverting Marx circult of $\sim 480-\mathrm{kJ}$ axinun energy storage at 20-kV charge. The Marx circuit output, F1g. 9, is a dc ground through $L_{3}$ and $L_{2}$ as are the other Marx c1rcuits in the syaten, thus ensuring that the machine is safe to work on at all timen, except during the firing cycle.

In operation, in the fuse node, $C_{2}$ and $C_{2}$ are charged to some voltage $V_{0}$. When Swl and Sw2 are fired, $-2 v_{0}$ la applied to the cables feeding the machine. Current flow through $L_{m}$, ande up of switch, capacitor, and cable inductance, and $L_{5}$, the drum Inductance, and the fuse. The maximum current that can be supplied into a short circuit at the fuse is $~ 1.5 \mathrm{kh}$ per quadrant.

The plasm current can be crowbarred by Sw5 to lindt the current to the range of 40 to $200 \mathrm{kA}$ with I valuea of $2 \times 10^{12} \mathrm{~A} / \mathrm{a}$.

Another variation of this clrcuit used in the experinent is to put a current linting series

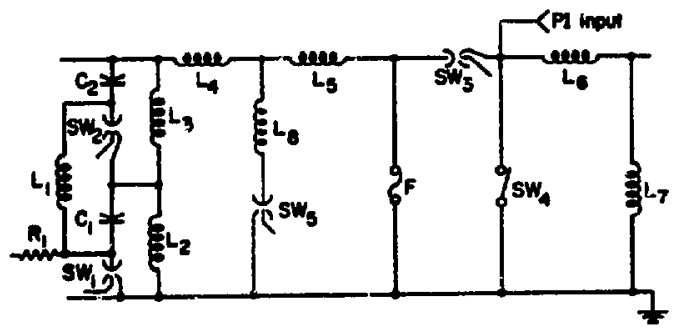

Viluse rabulaled ere tor each quadront

$$
\begin{aligned}
& c_{1} \Delta c_{2} \sim 300 \mu \mathrm{F} \\
& \text { F Fun } \\
& L_{1} \mathrm{~L}_{2} \mathrm{et} \mathrm{L}_{3} \sim 7 \mathrm{mH} \text { each } \\
& L_{4} \text { soures induetones }-19.2 \mathrm{nd} \\
& L_{5} \text { Drum inductance } \sim 35-160 \mathrm{n+1} \\
& 4 \text { Hooder and witch inductonce }-30 \mathrm{nH} \\
& L_{7} \text { Loed inductence } \sim 60 \mathrm{nt} \\
& \text { te Crewbar induclance }
\end{aligned}
$$

sw, s sw. irigotion wark gep Sw. Explotive erriwar Sw's Spork Gof wrowber

F18. 9. Electrical schenatic for $2 T-1$ inductive energy storage syatem. 
resistor (R) in place of Sw3. The current risetime is now the $L / R$ time constant of the circuit, which can be $\imath 0.6 \mu \mathrm{s}$, and decay time is $\mathrm{RC}$, which is 75 us.

Section IV gives a detalled discussion of the inductive storage and fuse system.

In che slow wode the fuse is removed and switch Sw3 is short circulted. When Swl and Sw2 are fired, $C_{2}$ and $C_{2}$ are discharged in sertes through $L_{4}, L_{5}$, $I_{6}$, and $L_{7}$. Primary current of up to $1 \mathrm{MA}$ per quadrant can be supplied in this mode.

Sw4 is an explosive switch used to provide a metal-to-metal crowbar circuit (see Sec. V).

IV. DESIGN OF THE INDUCTIVE ENERGY STORAGE SYSTEM USING EQUIVALENT CIRCUIT COMPUTER CALCULATIONS

The electrical circuit schematic (Fig. 9) and the physical layout of the discharge circuit are described in Secs. II and III. The characteriatics of the magnetic energy storage system with fuse switching have been previously reported. ${ }^{15}$ This section presents the results of numerical calculations used to predict the operation of the experiment with fuses. Figure 10 presents a simplifled schenatic useful in underatanding a nultiple fuse system. The extrapolation from the one- to the four-

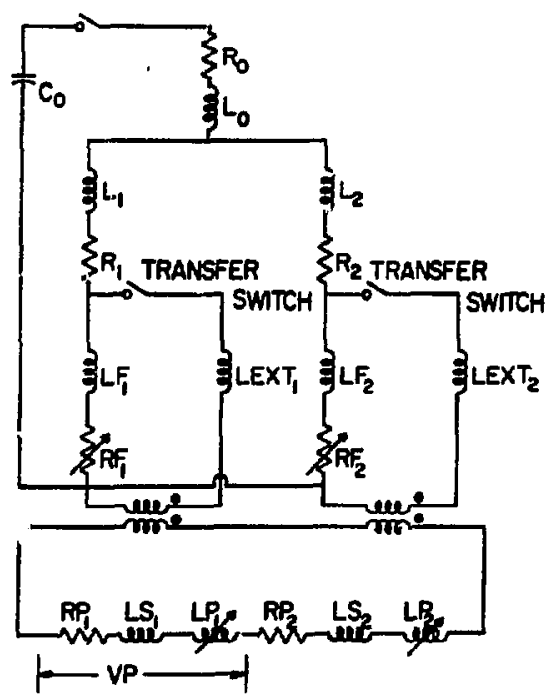

Fig. 10. Simplified schematic of multiple-fuse Induct Ive energy storage circuit. fuse operation introduces the sinultaneity question. Fuse tests show there is an average jitter of 0.2 He with 0.5 us being the maximum deviation. Inasmich as the half-width of the voltage pulse also is $\sim 0.5 \mathrm{ks}$, such a lorge fitcer would result in reduced electric flelds and large nonbaianced currents in the dr:m. Hence there must be sufficient mutual coupling among the fuses to force simultaneous operation.

The equivalent circuit shown in Fig. If is used to analyze a two-fuse coupled circuit rather than the four-fuse systen actually used. Energy storage occurs in $L_{0}$, while coupling between fuses is $1 \mathrm{im}$ ited by $L_{1}, L_{2}$ and $R_{1}, R_{2}$. The fuses appear as vartable resistors $R F_{1}$ and $R F_{2}$. At a predetermined voltage, the transfer switch is clused and current is transferred to the 2 pinch. Coupling is accomplished by a transformer which is assined to be 1deal. The $z$ pinch appears as variable inductances $L P_{1}$ and $L P_{2}$, whose functional dependences are derived from the snowplow model. An initial $b_{2}$ hias field is included in the calculation, subject to the flux conservation conditions. Plasma pressure is not included; circuit parameters are calculated from the dimensions and gecmetry of the experiment. Exprerimental values of $L_{1}, L_{2}$, and LEXT1, plus LEXT2, are obtained using analogue meusurenents.

Figure 11 shows the current flow and magnetic field lines determined from a resistive analog for the case of mismatch in the operation of adjacent fuses. Current is diverted from one fuse to the other along the flow lines shown. From such results, the Inductance between the fuses is calculated to be $14 \mathrm{nH}$.

Dynamic resiztance of the fuses is determined from published tables; ${ }^{5}$ which give values of resistivity as a function of internal energy up to the onset of fuse vaporization; beyond this, resistiv1ty is determined from actual measurements. ${ }^{16}$ The regults are shown in F1g. 12 as plots of fuse resistivity versus internal energy density for copper foil. A least squares fit over three sections of the resistivity curve is used to give analytic expresstons for use in the calculations. 


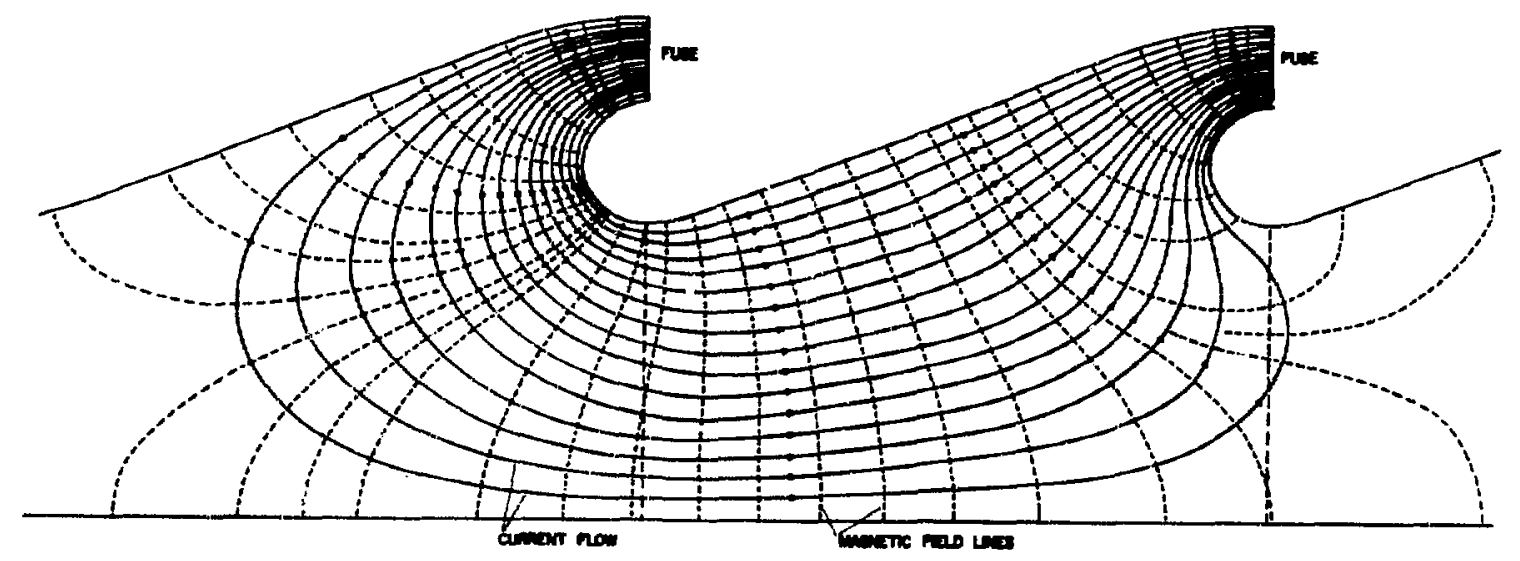

F18. 11. Current flow and megnetic fleld lines for a caue of miantched fuses.

Resistivity (ohm-a)

$$
\begin{aligned}
\rho= & 2.06 \times 10^{-1} \exp \\
& \left(4.51 \times 10^{-6} \mathrm{E}\right) \\
D= & 4.98 \times 10^{-0} \mathrm{exp} \\
& \left(1.61 \times 10^{-6} \mathrm{E}\right) \\
\rho= & 1.7 \times 10^{-7} \mathrm{exp} \\
& \left(0.655 \times 10^{-6} \mathrm{E}\right)
\end{aligned}
$$

Incernal jergy Rarge (E. In $\mathrm{H} / \mathrm{kG}$ )

$$
\begin{aligned}
& 0 \rightarrow 0.3 \\
& 0.3 \rightarrow 1.3 \\
& 1.3 \rightarrow 6.0
\end{aligned}
$$

To test the applicability of this equivalent circuit calculation, results of cosputed and mensured waveforms for current and voltage for the single fuse case of the earlier linear 2 -pinch experiment ${ }^{5}$ art compared and agree within the experimental accuracy of $\sim 10 \%$ as show in Fig. 13. (In this calculation, $L_{2}$ and $R_{2}$ are made very large so as to remove the second fuse from the circuit.)

For the toroidal case, the achlevement of similar fusa-voltage characteristics is of prinary tmportance. This is teated using the equivalent circult calculations by Introducing a tining difference of approxiantely three timen the normal jitter between fuses by using different fuse cross sections $\left(S_{1}=35.0 \times 10^{-6} \mathrm{~m}^{2}\right.$ and $\left.S_{2}=28.6 \times 10^{-7} \mathrm{~m}^{2}\right)$ In the two legs of the equivalent circuit. Results calculated using these crose sections with the single-fuse technique above show that the current and voltage waveform attain peak values with ح 2-us tise difference (F1g. 14). To deternine the effectiveness of coupling of the fuses with this tining difference, the equivalent circuit calculatlons are repeated using the two different fuses with appropelate values of $\mathrm{L}_{1}, \mathrm{~L}_{2}$ and $\mathrm{R}_{1}, \mathrm{R}_{2}$. Calculations whow that the voltage charactexistics coincide within 17 as in F1B. 15. The two voltage characteriaticu cannot be resolved from one another

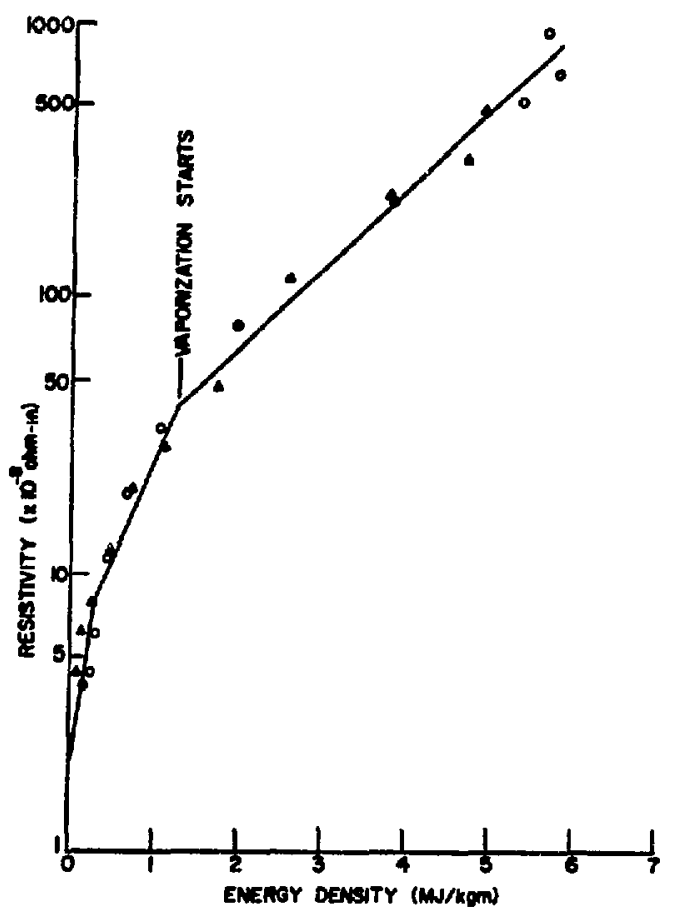

Fig. 12. Fuse resiotivity as function of internal energy density for copper foll. 


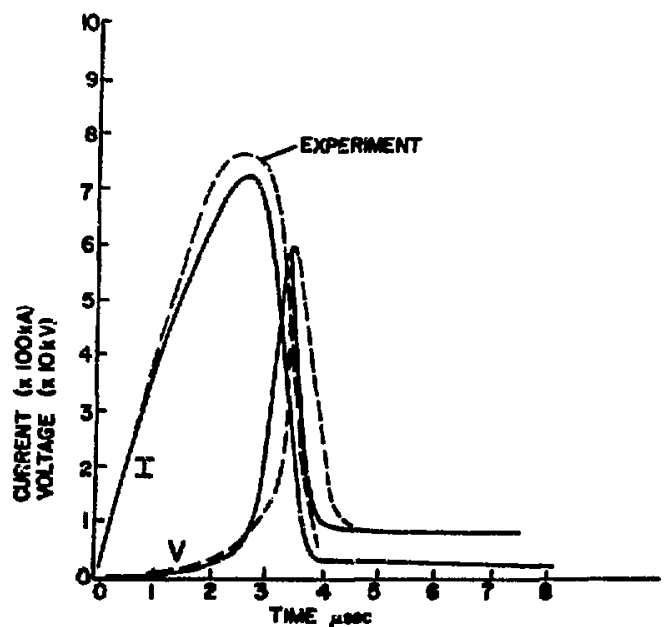

F1g. 13. Comparison of computed and neasured current and voltage waveforms for a single fuse.

within the accuracy of this plot. Numerous firings of the four-fuse byatem confirm both simultaneity and reproducibility of the voltage wavefocm applied to the plasma.

Physically, the fuses are sheets of plastic, 0.25 m square, 0.02 a thick; along one edge the foll

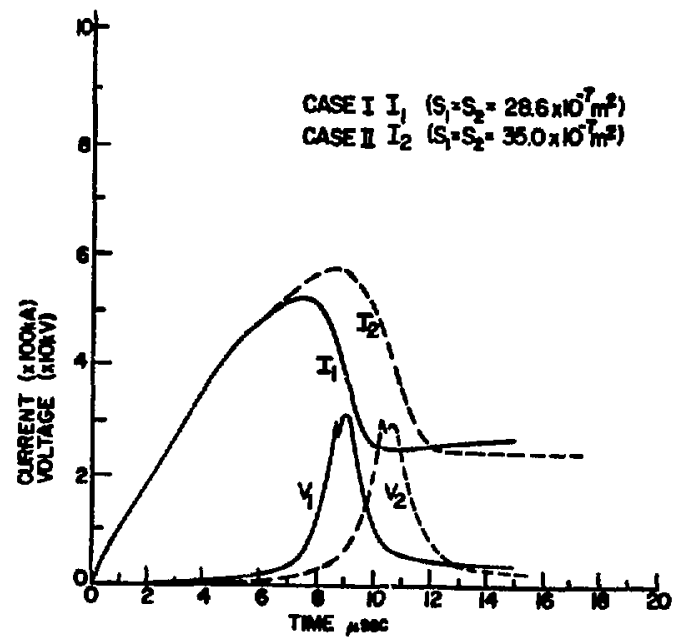

F18. 14. Current and voltage wavefores resulting from foila of different thicknesses of copper.

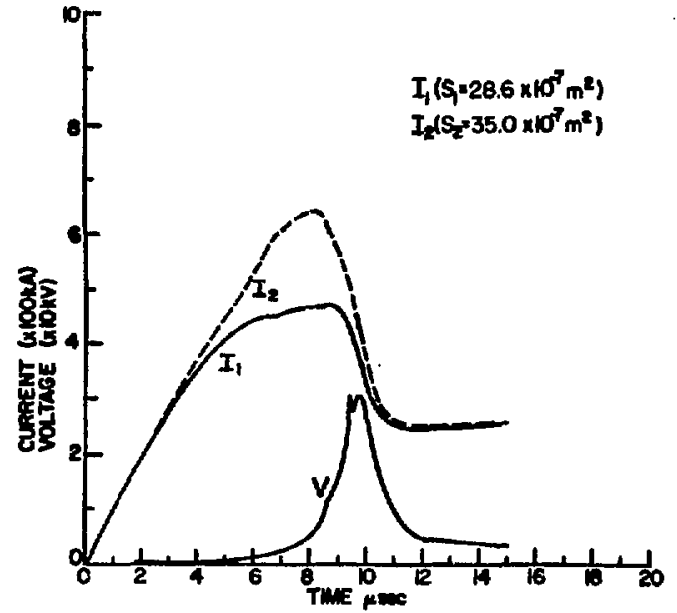

F1g. 15. Output voltage of mutually coupled disoimilar fuses cannot be resolved as the sum of two voltages.

Is centered and also wrapped around that edge. A typical foil is copper, $2 \times 10^{-5} \mathrm{~m}$ thick, $0.12 \mathrm{~m}$ wide, and 0.15 m long. Connections are made to the ends of the foll, away from this folded edge, and the entire foil section is imersed in a sealed pouch of glane beade $10^{-4}=$ diameter. (See F1g. 16.) Detalls of construction may be found in the annual report $^{17}$ and design considerations in the

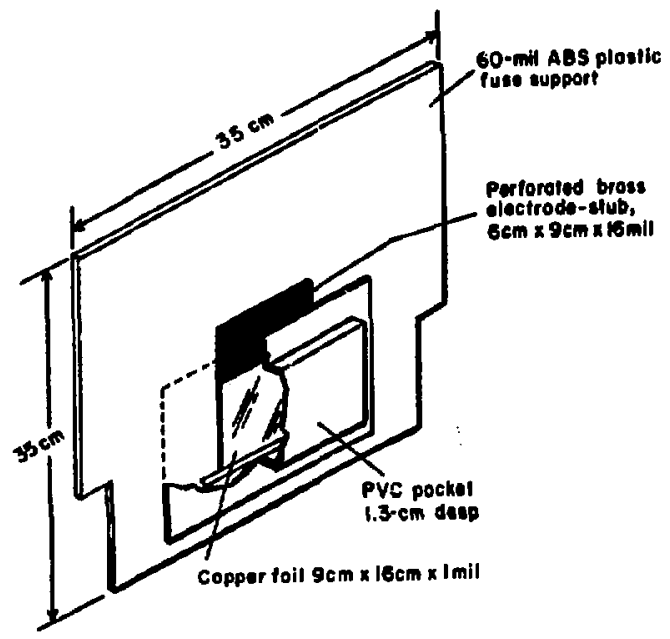

F1g. 16. Photograph of the fuse. 
11terature. ${ }^{26,18,19}$ The fuse package readily absorbs $21 \mathrm{~kJ}$ of energy without destroying Itself, and being a sealed untt, may be used in any position. This inverting feature can double the energyhandling capabllity of this fuse-driven system.

\section{v. MAGNETIC FIELD ERRORS}

In the theory of otable magnetic field configurations for the toraidal pinch, the flelds are assumed to have complete toroldal axial symmetry and to be free from perturbations and nonuniformities. Even small magnet1c fleld errors may have undesirable effects on plasma equilibrium and containment. This has been observed in Tokamak devices, 20021 the Stellarator, ${ }^{2}$ GGA Octupole, ${ }^{23}$ and the G.A. programmed pinch device. ${ }^{24}$

In the 2T-1 device, tha current through the parallel plate transulssion lines at the torus feedpoints will produce a significant transverse field error within the torus in the region of the feedpoint gap unless corrections to the direction of current flow are made. The current through the IInes can be considered as having two components-the magnetization current and the plasma image current. The magnetization current flows on the outer surface of the primary and provides the flux change that generates the toroidal electric field in the discharge tube. The use of Iron cores reduces this current component to a sufficlently low value so that the fleld errors due to this source are very sma11. The plagma tmage current flows on the inner surface of the torus primary with an azimuthal distribution determined by the position of the plasma colum inside the discharge tube. At the feedpoint gaps, this current must flow out and return along the parallel plate lines without producing magnetic field distortions in the region of the plasma. These distortions will occur unless special precautions are taken to obtain a radial current flow pattern In the transition region between primary and parallel plate 1ines.

A. Calculation of Equilibrium Plasma Image Current Distribution

The plasma Image current density is proportional to the pololdal field at the Inner surface of the primary. An axisymmetric toroldal MHD equilibrium computer code was used to compute the variation in this surface field for toroidal diffuse pinch equilibria having hollow pregsure profiles and reverse toroidal fields outside the pinched plasma. Sample fleld and pressure plots for pololdal beta $\beta_{p}$ - average plasma pressure/magnetic pressure due to the average poloidal field at the wall) of 0.1 , 0.4 , and 1.0 are shown in Eige. 17a, b, ant $c$, respectively. In the figurea, the plamna presgure was varied to change $B_{p}$; all other parameters, Including the shape of the plasma profile (as a function of pololdal flux), were held constant. In these exapples the rat1o of the peak plasma pressure to the pressure at the magnetic axis was 1.3. The peak of the pololdal field is held constant in this set of f1gures, so the primary change readily apparent in the pololdal field 18 the outward radial shift in the profile. The $6 \%$ change in the toroidal field is the adjustment it makes to waintain pressure balance.

A sertes of computer runs was made to see how the plasma profile width (at half-maximim) and $\beta_{p}$ affect the pololdal field at the outer wall. Figure 18 shows the effect varying $B_{p}$ has on the polotdal field at the wall for a fixed profile width. One notable feature of these calculations is that, for a riven width of pressure profile, there is a $\beta_{p}$ value at which the poloidal field magnitude along the conducting wall is nearly constant.

The value of the ratio of the maximum to minimum polotdal fleld along the outer wall of the torus

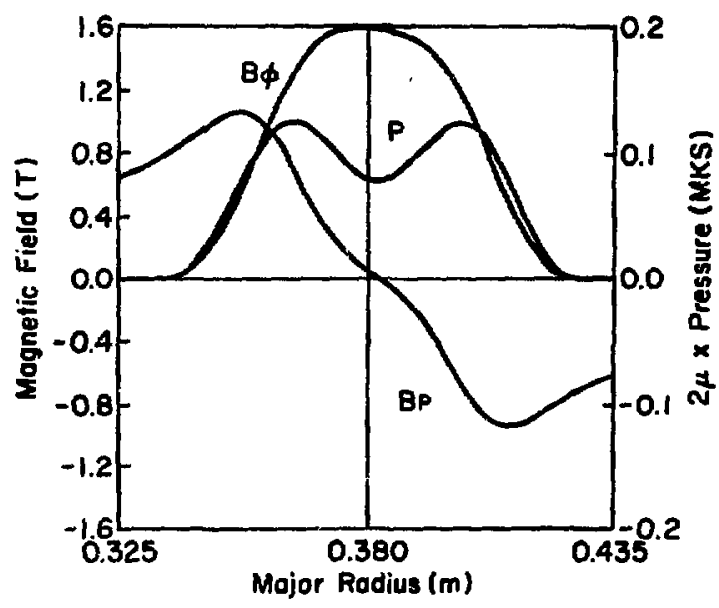

Fig. 17(a). Field and pressure plots for $2 T-1$ for a pololdal $\beta$ value of 0.1 . 


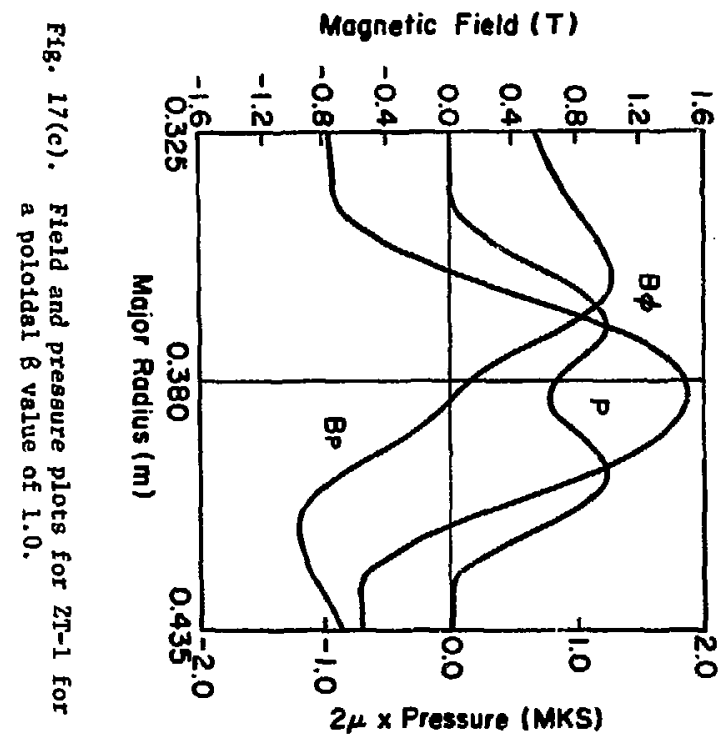

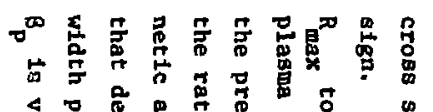

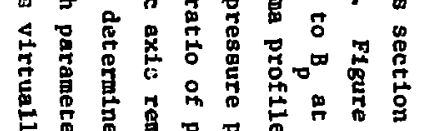

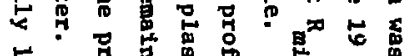

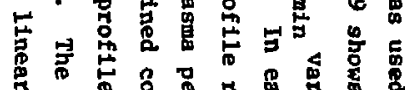

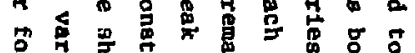

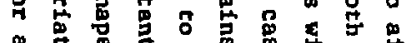

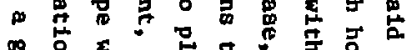

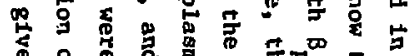

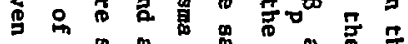

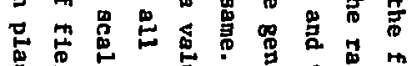

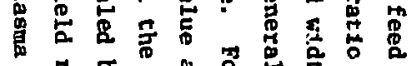

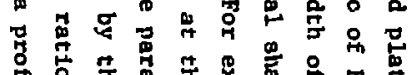

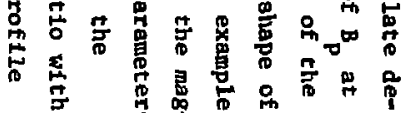

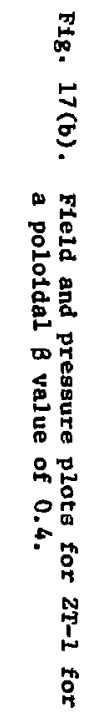
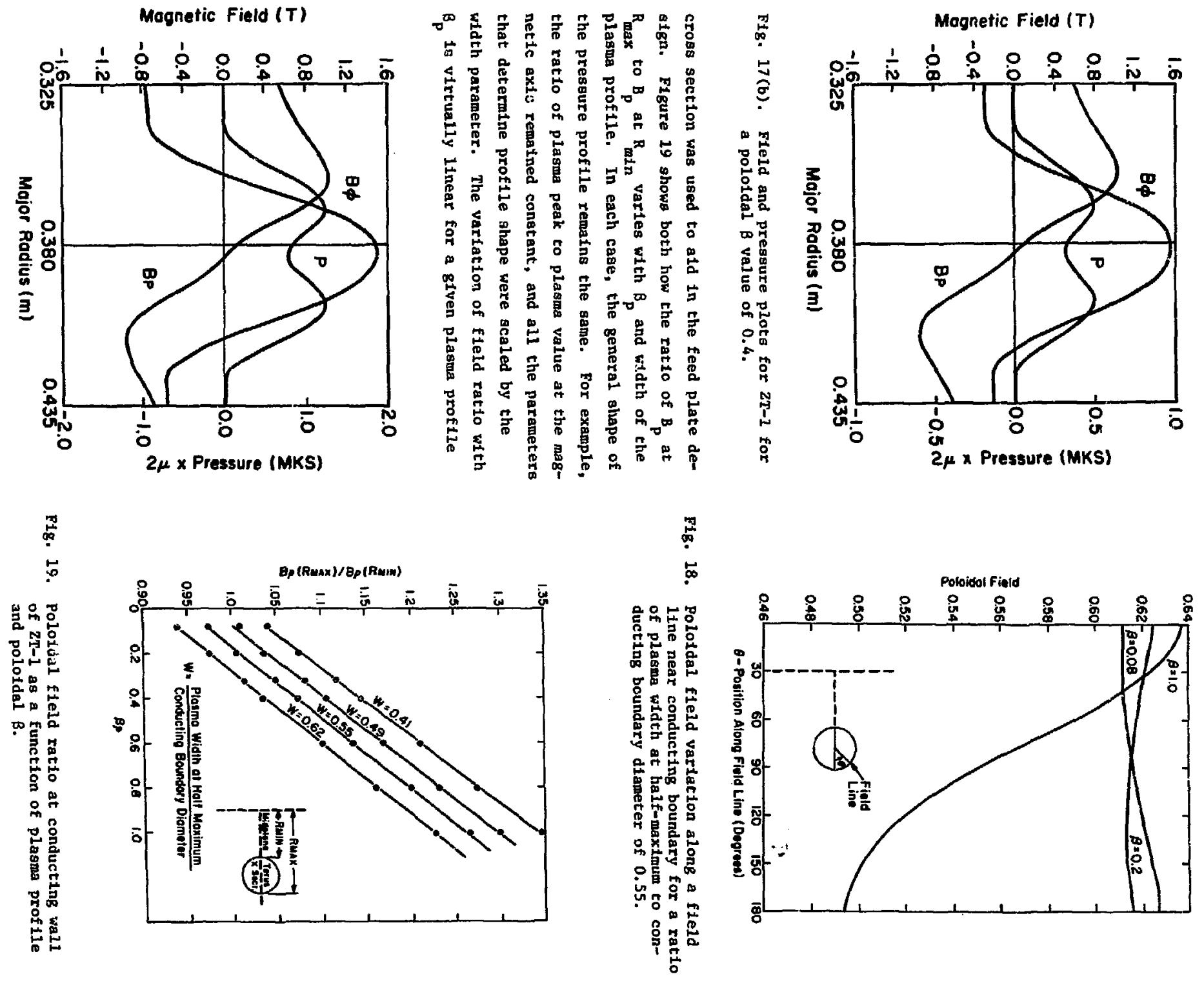
width. MHD stability calculations indicate that the plasma width should be greater than about onehalf the conducting boundary diameter and that $B_{p}$ should be less than 58\%. Vestrable operating conditions are well below these critical stability limits, thus a destgn which allows pololdal field vartations up to $10 \%$ along the minor circumference Is adequate.

The varlation of the magnetic center shift with $B_{p}$ and width is shown in Fig. 20. The greatest shift occurs at high beta and with narrow plasma profiles. The variation of shift with $\beta_{p}$ is approximately linear for a given width.

B. Measurement and Correction of the Feedpoint Kagnetic Field Error

Two full-acale mock-ups of the feedpoint sectiun were used to deteratne the transverse fteld error and to test the effectiveness of corrective measures.

The first mock-up consisted of a parallel plate transmission line of the same width and length as those in $2 T-1$, and two aluminum straight cylindrical tubes of $11-\mathrm{cm}$ 1.d. to simulate the torus primary. Since the above theoretical calculations indicate a nearly uniform pololdal distribution of toroldal current for plasma equilibrium, the effects of toroldal curvature were neglected. The outer ends of

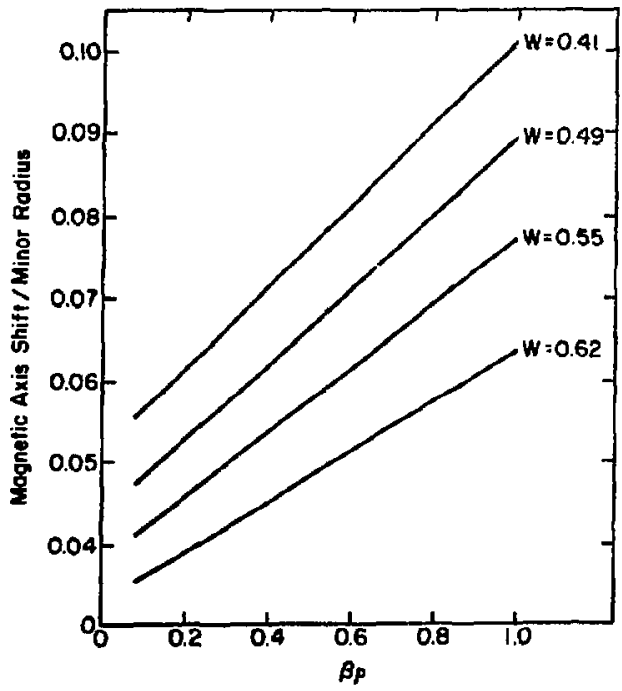

Fig. 20. Magnetic axis shift as a function of plasma profile width and pololdal $B$. the cylindrical sections were closed of $f$ by metal plates foinad by an axial 1.6-cm-diamecer rod that aimulated the plasma current. The mock-up circuit was driven by a damped oscillatory discharge (u $5 \mathrm{kA}, 15-\mathrm{ks}$ period) connected to the parallel plates at the pocition of the transfer switch in ZT-1.

Measurement of the initial field asymetry before modifications was made with a single-turn flux loop mounted on an $211-\mathrm{cm}-\mathrm{d}$ lam cylindrical phenolic form Inside the simulated primary. The loop was rotated to measure the magnitude and aztmuthal vartation of the pololdal field at the feedpoint. The results, shown in Fig. 21, indicate a transverse fleld superimposed on a constant pololdal $B_{\theta}$ component. The magriftude of the fleld due to the $\sim 5 \mathrm{kA}$ axial current at the position of the flux loop was 198 G - Indicated by the dashed line in the figure. superimgosed on this is a transverse field error at $\sim 45^{\circ}\left(\approx 20 \%\right.$ of $\left.B_{\theta}\right)$ that adds to the $B_{\theta}$ component at $\theta=0^{\circ}$ at the side of the feedpoint nearest the current input, and subtracts at $180^{\circ}$ on the opposite side of the primary. (This field error is of approximately the same relative magnitude reported by Kerst et a1. ${ }^{24}$ )

Three techniques for eliminating this ileld error were tested: (a) a split ring cylindrical flux divertor inserted inside the simulated primary across the feedpoint gap, (b) grooved interlocking flanges in the parallel plate lines coaxial with the primary, and (c) current distribution control by cutting Inductive gaps in one of the parallel plates.

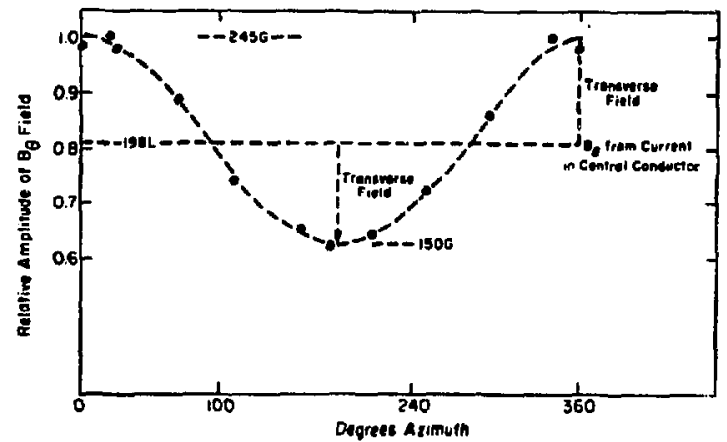

F1g. 21. Varlatton of poloidal magnetic fleld component around minor circumference due to transverse field error. Measurements made with full-scale mock-up. 
Measurements of the magnetic field were made with flux loops orfented to measure transverse, axial, and poloidal field components. Results of measurements of the reduction of the transverse field error with cylindrical divertors of 4-, 7-, and 15-cm length are show In F1g. 22. Copper cylinders of $0.08 \mathrm{~cm}$ thlakness were used with 0.25 -cm-thick insulation to avold short circuiting the feedpoint gap. A1so, an Insulated longitudinal gap was cut in each cylinder, necessary in the $\mathrm{ZT}-1$ system to admit the toroldal stabllizing field. These cylindrical inserts tend to shield the volume inside the feedpoints and divert the trangverse field away from the discharge region. However, the shielding is linted because there remain flux paths around the exds of the divertors, and the reluctance of the magnetic path is changed significantly only by the longer cylinders. The extension of the transverse fleld flux lines around the ends of the divercor cylinders was apparent in measurements with flux loops mounted on a coaxial bucite cylinder that was moved along the axial conductor. The effectiveness of the shielding increased with divertor length but there was also a corresponding increase in the system Inductance because of the

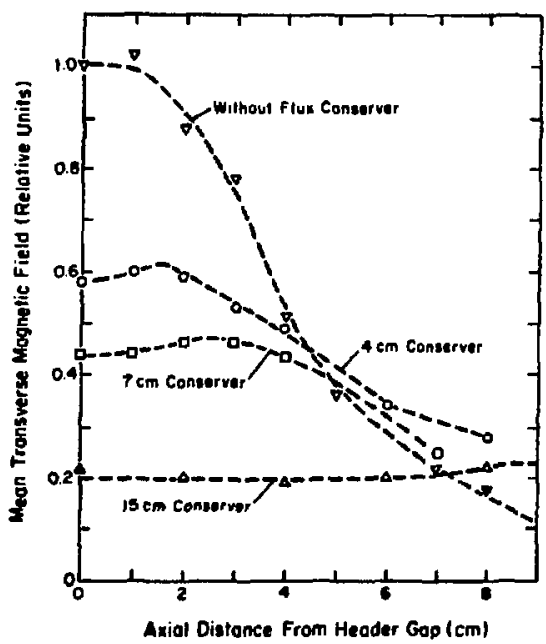

F1g. 22. Measurements of reduction in transverse magnetic error field with metal cyclinder or flux divertors of indicated lengths inserted across the feedpoint gep of the rock-up.
Insulation space required. Because of this factor, the divertors used ultinately in the $2 T-1$ machine were 1 imited to $\sim 6-\mathrm{cm}$ long, $11^{\circ}$ sectors. From Fig. 23, these should decrease the transverse error fleld by only a factor of $\sim 2$ and additional field corrective measures are needed.

This mock-up was also used to test the effecclveness of reducing the error fleld by means of circular tongue and groove patcerns ${ }^{25}$ machined into the parallel plate lines concentric with the primary. Two such tongue and groove sections were machined 1nto the mock-up header at $21-$ and $22-\mathrm{cm}$ radil with oppositely directed groove depths of $1.25 \mathrm{~cm}$ and $1.75 \mathrm{~cm}$. The reduction of the transverse field Inside the primary at the feedpoint gap was a factor of $\sim 2$. Deeper tongue and groove sectlons at smaller rad11--nearer the primary--should be more effective. But because of the difficulties Involved in insulating these areas for $\imath 80 \mathrm{kV}$, this technique was not used in 2T-1.

The technique of machining slots in one of the parallel plate transmission lines to control the current distribution was adopted for the $2 T-1$ system. The slotted areas are effectively trimmed inductances which are varfed by changing the length

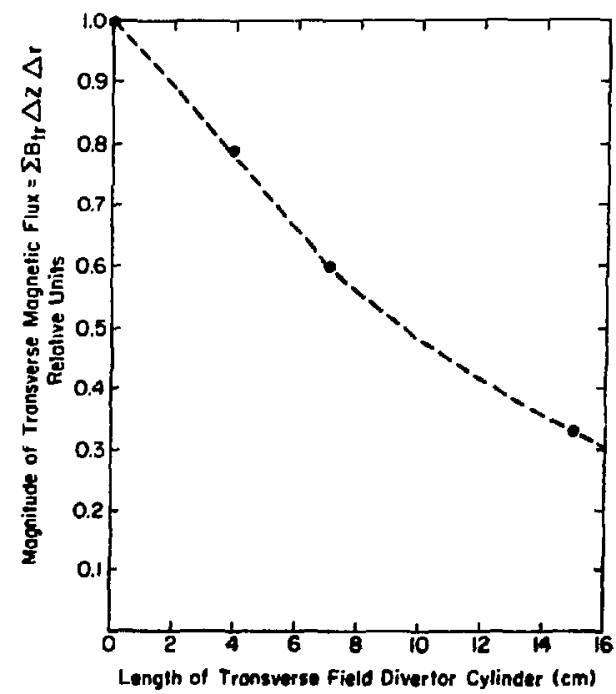

Fig. 23. Magnitude of tranoverse magnetic field erfor versul length of flux divertor cylinder inserted at the feedpoint bap of rock-up. 
and width of the holes. A first approximation to the distribution and size of the slots required was obtained using the resistor paper analog method. The paper was cut to scale to stmulate one of the parallel plate lines and the current flow pattern traced with probes. Holes were cut in the resistor paper to force the current distribution, at the position of the primary to transmission Ifne junction, to have only a radial component toward the primary axis, and to have a uniform current density around the primary clrcumference.

A second full-scale mock-up of one of the parallel plate lines was then constructed with the alot pattern determined from the resistor paper analog tests. The mock-up c1rcult was driven by a capacitor discharge connected at the position of the trangfer switch. A feedthrough bolt at the position of the torus axis was used to complete the circult. A thin phenolic disk containing magnetic fleld probe colls was nounted between the plates and rotated about the feedthrough bolt. The probe coils were oriented to measure the azimuthal and radial field components at the radius of the primary inner surface. Furcher modifications of the slot pattern were made by trial and error until a uniform azimuthal field distribution with $\& 2 \%$ varlation was obtained. The final transmission line layout is shown in Fig. 24. The plates are held together by three Insulated through-bolt clamps

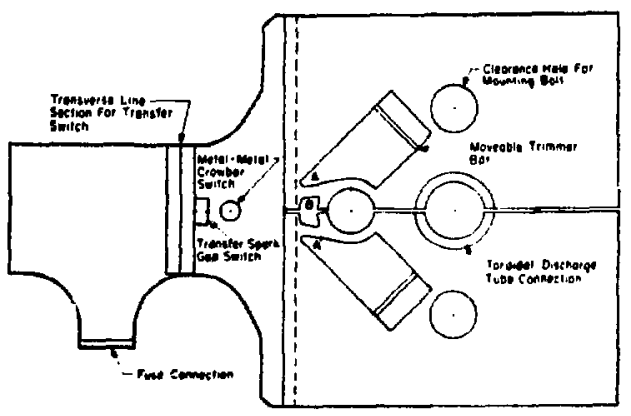

F1g. 24. Final pattern of the parallel plate tranemiseion line section extending fros the fuse to the torus feedpoint showirn the eounting holes for through-bolt clamps and the pattern of Inductive cutoute to control current flow and einim!se transverse angnetic ffeld error. inserted through the counterbored holes shown in the figure. The additional three areas cut out of the plate to control the current distribution are labeled $A, A^{\prime}$, and $B$. Trimmer bars are inserted across $A$ and $A^{\prime}$, as shown, for additional control of the current flow. Without the cutouts $A, A^{\prime}$, and $B$, the asyzanetrical field distribution shown in Fig. 25 (a) 18 obtained. With the holes, A, A', and $B$ cut out, the field vartation shown in Fig. 25 (c) is obtained. The field error is overcompensated so that the field asymmetry is then reversed with the higher current density, $J_{r}$, on the side of the primary opposite the transfer switch position. This pattern would be used if the plasma equilibrium is off center by 4 un as described above-ree Figs. 19 and 20. With the insertion of 7-mm-wide trimmer bars at $2.5 \mathrm{~cm}$ from the ends of gaps $A$ and $A^{\prime}$, the uniform current distribution shown in Fig. 25(b) was obtained. This "uniform current" configuration was assumed in the $2 T-1$ experiment.

c. Field Errors In Poloidal and Toroldal Fleld Due to Pump Port Perturbations

There are two 1.9-cm-diameter pump ports in each quadrant of the aluminum primary of the $\mathrm{zT}-1$ device. The holes allow the use of $1-\mathrm{cm}-1 . d$, ceramic tubes for evacuation of the discharge tube. The magnetic field perturbations on the poloidal and toroldal fleld components cauged by these holes have been examined numerically.

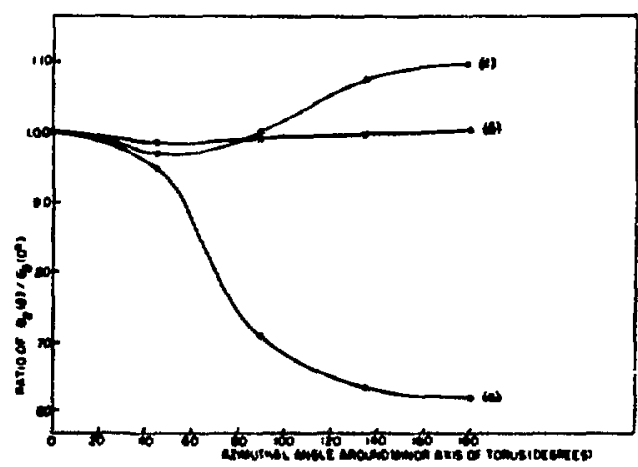

Fig. 25. Aximuthal feed place field dietribution; undercompenated (a), overcompensated (c). and correctly compenseted uith trimer bara (b). 
1. Toroldal Fleld Perturbat lons. Since calculation of field divergence Into round holes in the primary is difficult, the model used for computation assumed a cylinder the dimensions of the primary with an azimuthally symetrlc cut, $1.9 \mathrm{~cm}$ wide, taken around the minor circunference. A $2.85-\mathrm{cm}-$ dlam coaxial center conductor was assumed to simulate the plasma pinch. This forced the $B_{z}$ field lines at this radial position to be parallel to the minor axis. A numerical axially symetric equilibrium code then determined the position of $B_{z}$ fleld lines and the strength of the magnetic fleld. In Fig. 26 the strength of the $B_{z}$ field is plotted along a radius in the plane midway in the cut, showIng a comparison of colculated and experimental results obtained with probes. The fleld drops of $f$ as expected with a $21 \%$ reduction at the pump port, $r=$ $5.2 \mathrm{~cm}$. Flux 1 ines $22.5 \mathrm{~mm}$ from the porcelain wall w11l Intersect the wall at the cut. As a round hole would have a smaller effect than the cut assumed in the calculation, a displacement of $\varsigma_{2} 2 \mathrm{~mm}$ is possible.

2. Pololdal Fle1d Perturbations. The geometry shown in Fig. 27 was used to compute the diatortion of the pololdal fleld by the pump ports. The

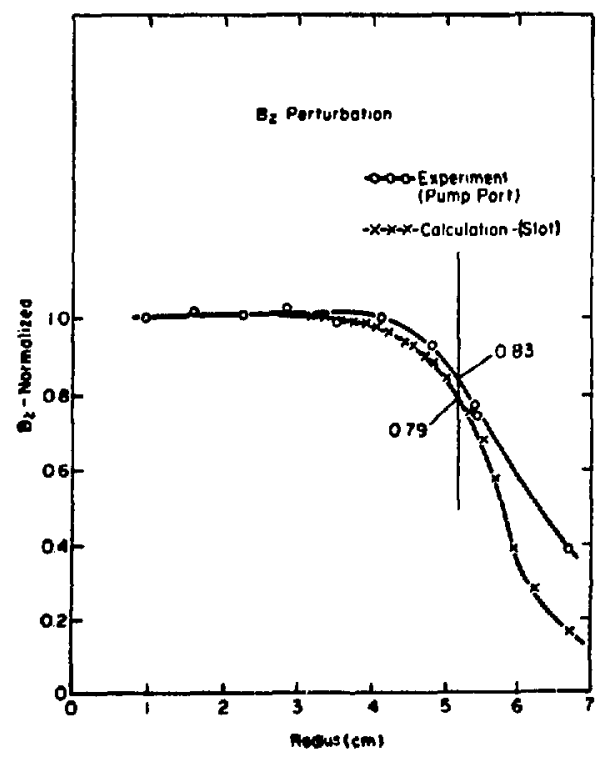

FI8. 26. Results of computed and measured values of magnitude of the $B$. field along a rad1us through a puap port. (o)

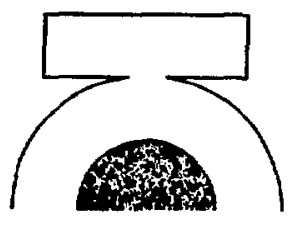

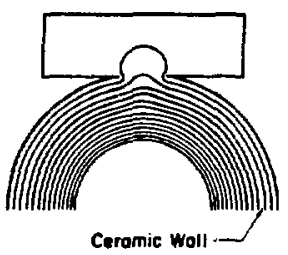

(b)
F18. 27. The radial displacement of pololdal lines at the region of a pump port.

dimenstons are those of $\mathrm{ZT}-1$ with an Inside conductor that carrled a 2 current elther one-half or three-quarters the diameter of the primary. The model assumed for computation assumes two slots (one not shown) that are continuous around the major c1rcurference and located on the median plane at the position of the pump ports. Figure 27 a shows the conductors and F1g. $27 \mathrm{~b}$ shows the computed pololdal flux 11nes. The maximum deflection of the fleld lines at the slot (or pump port) is about 2 um at the ceramic wall.

\section{VL. MAGNETIC CORE DESIGN}

The use of magnetic cores with toroldal discharges offers three advantages: (1) reduced expansive hoop forces on the primary, (2) reduced field errora at the feedpoints caused by the magnetization current which is decressed by $>2$ orders of magnitude with the use of the cores, and (3) more efficlent use of the current since the magnetization component 18 decreased.

Four magnet1c cores are used in the experiment. Each core 18 made up of seventeen $0.44-m-$ wide tapewound sections. The sectlons have an outer diameter of $0.686 \mathrm{~m}$ and Inner diameters varying from 0.25 to $0.594 \mathrm{~m}$ to accommodate the curvature of the toroldal discharge tube. The ferromagnetic tape is made of 50/50 nicke1-1ron alloy of 0.0254-mm th1ckness and 12.7-um widch. The stacking factor is 2 0.8 and the material resistivity is $45 \times 10^{-8} \Omega-m$.

The thin tape 18 chosen to permit rapld penetration of the magnetic flux into the core with minImal applied magnetization current. A typical voltage waveform required for the experiment 18 shown in F1g. 28. The magnetization current required to Induce this voltage is calculated using the saturation wave theory of Wolman and Kaden. ${ }^{26}$ This approach was used by Winter, Kuenning, and Berg $^{27}$ to determine the magnetization current necessary to 


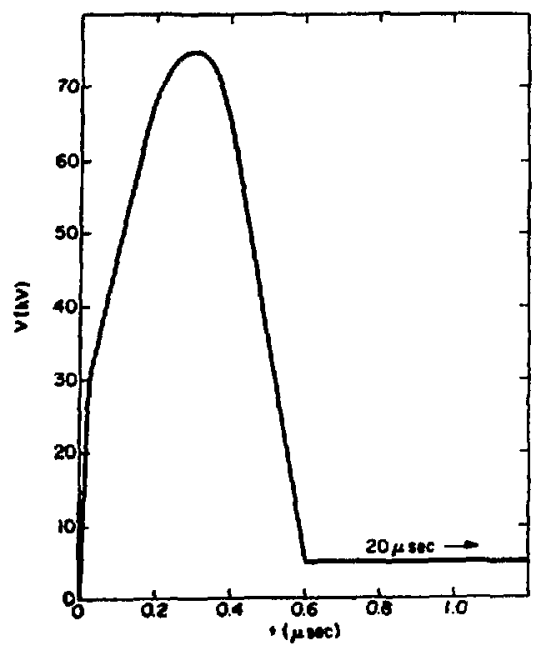

Fig. 28. Ansined voltage $V$ per quadrant as function of time, $t$.

produce given volcage pulses in single magnetic sections for the Astron device.

To calculate the performance of a combination of sections having different inner diametera, it is convenient to culculate firat the voltage induced in - single section by a given agnetization current $I(t)$. The voltage $v_{n}(t)$ induced in a section of Index $n$ is (in axs untes):

$$
V_{n}(t)=2 \frac{S w}{d} \sqrt{\frac{\rho \Delta B_{s}}{\pi}} \frac{I(t)}{\sqrt{f^{t} I(t) d t}}\left(\sqrt{r_{o n}}-\sqrt{r_{1 n}}\right),
$$

where $w_{2} d, \rho$ are the vidth, thickness, and resistivity of the tape aterial, $S$ is the stacking factor, and $A B$, is the magnetic field change at the saturation wave front. The value for $r_{1 n}$ is given by

$$
\begin{aligned}
& r_{1 n}=r_{1 n} \text { for } r_{0}<r_{1 n} \\
& r_{1 n}=r_{\text {a }} \text { for } r_{1 n} \leq r_{0} \leq r_{\text {on }} \\
& r_{1 n}=r_{\text {on }} \text { for } r_{0}>r_{\text {on }}
\end{aligned}
$$

where $r_{a}$ is the radius of anturation given by

$$
r_{0}=\frac{4 \rho}{\pi d^{2} \Delta B_{0}} f I(t) d t
$$

and $I_{\text {In }}$ and $I_{\text {on }}$ are the Inner and outer radil of the $n$-th section. The equations for $V_{n}(t)$ are sumed over all gections making up a core to give the tctal induced voltage $V(t)$. The term $I(t)$ is factored out and the expression solved numerically to give the magaetization current $I(t)$ for a given voltage $V(t)$. Figure 29 shows the magnetization current as a function of time corresponding to the voltage trace of Fig. 28 for two values of $\Delta B_{s}$ determined by the magnitude of the magnetic fleld reversal. The cores become saturated at 9 or $11 \mu \mathrm{s}$ for the values of $\Delta \mathrm{B}_{s}$ chosen. Before saturation, the augnetization current realins orders of magnitude below the $\sim 200-$ kA plasme current.

From the wagnetization current, the interlainar voltage is readily calculated. The higheat value occurring in the core 18 shown in Fig. 30 as a function of tine for the two values of $\Delta B_{s}$. During the initial peak, the highest voltage occurs at the inner dlameter of the core with a peak value of $1 \mathrm{~V}$ which 1a below the 2-V lintt get by the anufacturer. Near saturation, the highest interlaninar volcage occurs at the periphery. The large theoretical increase in voltage at full saturation coincides with the steep increase In the agnetization current and is damped by the finite inpedance of the

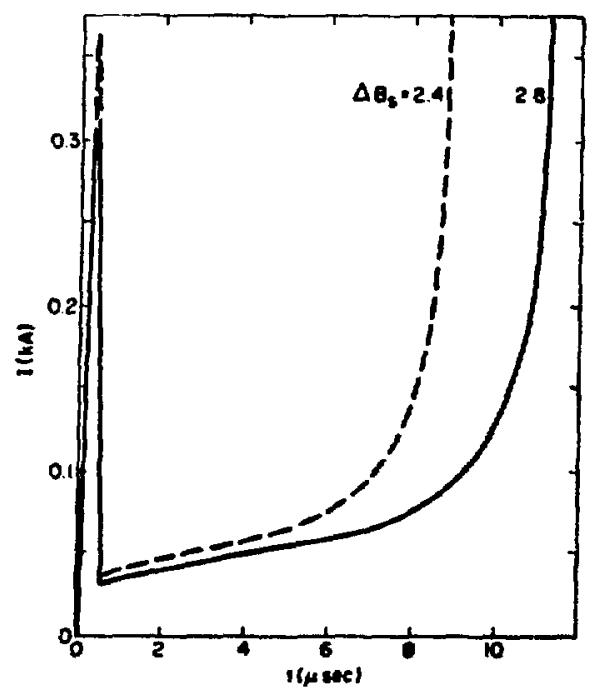

F18. 29. Calculated argnetization current 1 as function of time $t$ for two values of majtet $1 c$ field reversal $\Delta \mathrm{B}_{\mathrm{a}}$. 


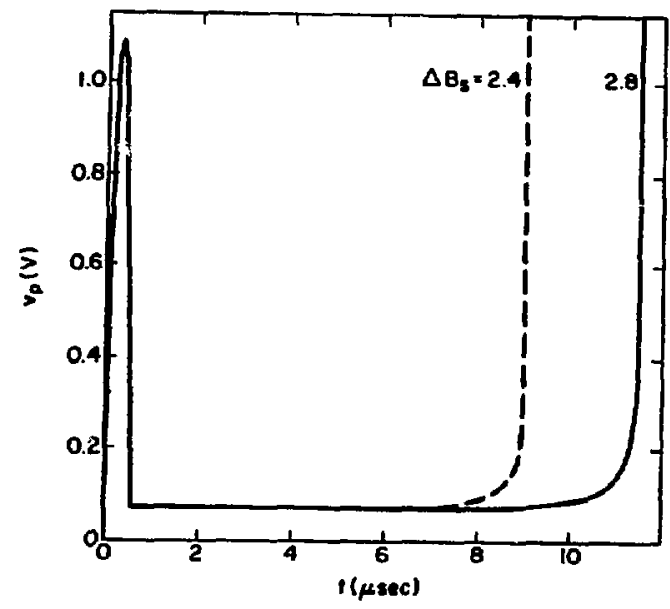

F1g. 30. Highest interlaninar voltage $v_{p}$ in the magnetic core as function of tine, $t$, for two values of asgnetic fleld reveraal $\Delta \mathbf{B}_{\mathbf{B}^{*}}$

energy storage circuit. In operation, no arcing of the cores has been observed.

\section{METAL-TO-METAL CROWBAR SWITCHES}

Low-Inductance crowbar awicches have been installed in the four feedplates of $2 \mathrm{~T}-1$. The design of this awtch is ahown in Fig. 31 and detalled by Dike and Kewish. ${ }^{2 *}$ Characteristics of the uwitch include a self-inductance of $\sim 3 \mathrm{nH}$, and a reaistance of $\sim 5 \mu \Omega$. Time of closure and $j 1 t$ ter is $\sim 11.0 \pm 0.3 \mu$ (where $t_{0}=0$ is defined as the start of current in the bridgewire of the detonator). Crowbarred currents ranging between 180 and $330 \mathrm{kA}$ show, without burning of the current contact, LiR decay times of $1.2 \mathrm{ma}$. Performance on the $2 \mathrm{~T}-\mathrm{l}$ experiment is within these electrical parameters, although camplicated by the planna load.

\section{ACKHOWLEDCHENTS}

The authors wish to express their gratitude to J. L. Tuck, R. F. Tauchek, H. T. Hotz, and E. L. Ribe for discuestone and encouragement, and to $E$. L. Kanp, K. Kewish, and R. Haarman for engineerint eupport. Thanks for cechntcal assiatance in the assombly, asintenance, and operation of the experimente siven with plessure to A. Brousseau, $W$. souman, D. Birkeze, C. Charltin, R. Holm, t. Iko, D. Jardine, A. Lopez, A. Rendon, and N. Salazar.

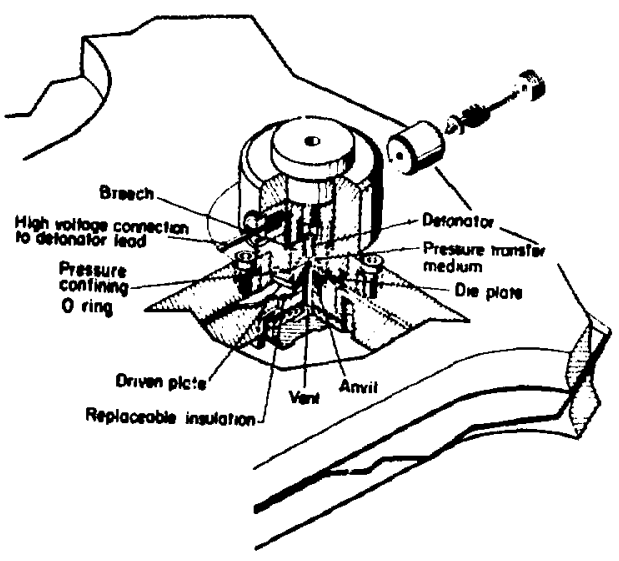

Fig. 31. Partially cut away drawing of explosive crowbar switch for ZT-1.

\section{REFERENCES}

1. T. Ohkawa, H. K. Forsen, A. A. Schupp, Jr., and D. W. Kerst, "Toroldal Discharge Experiments with Rapld Programing," Phys. Flulda 6, (1963) p. 846 .

2. D. C. Robineon and R. D. King, "Factors Influencing the Perlod of Iaproved Zeta Stability," Proceedinge, Plasma Physics and Controlled Nuclear Fusion Research, Novosibirsk, 1 , (August 1968), P. 263.

3. C. Bobeldijk, R. J. J. Van Heijningen, P. C. T. Van Dar Laan, L. Th. M. Ornatein, W. Schuurman, end R. F. De Vrien, "Properties of a Toroldal Screw Pinch Surrounded by a Constant-Pitch Mngnetic Field," Ibid, p. 287.

4. R. Wilhelm and H. Zwicker, "Experinental Observatione on a Toroldal Screw Pinch," Zeitechrift Fur Physik 240, (1970), p. 295.

5. J. N. D1 Marco and L. C. Burkhardt, "2 Pinch Driven by Magnecic Energy Storage," Proc. IV European Conf, on Controlled Fusion and Plasma Phys 1ce, Rone (Augunt 1970), p. 53.

6. J. A. Phillipa, "Proposal for A Shock-Heated Toroidal 2-Pinch Experiment," Los Alimos Scient if ic Laboratory report LA-4352, November 1969.

7. H. H. Rosenbluth, "Infinite Conductivity Theory of the PInah," Los Alamos Scientific Leboratory report $M A-1850$, (September 1954).

8. J. N. Di Mareo and L. C, Burkhardt, Los Alamos Scientific Luboratory Controlled Thermonuclear Research Progren Annual report, LA-4351-MS (1969), P. 54 .

9. M. Y. Clauker and E. S. Welbe1, Proc. Second U. $*$. Conf, on Peaceful Uses of Atomic Energy, 32. (1958), P. 161 . 
or L. 0 . Heflinger and S. L. Leonard, Div, of Plasma Phys., APS, Monterey Conf., J3 (1959).

10. H. A. B. Bodin, A. A. Newton, and N. J. Peacock, Nuclear Fusion 1 , $(1960)$, p. 54.

11. D. C. Robinson, Plasma Phys, 13, (1971), p.439.

12. D. A. Baker, L. C. Burkhardt, J. N. D1 Marco, P. R. Forman, A. Haberstich, H. J. Karr, L. W. Mann, J. A. Phillips and A. E. Schofield, Plasma ghysics and Controlled Nuclear Fusion Research, Vol. I, Madison, Wisconsin (1971), p. 203.

13. A, Habergtich, LoB Alamos Scientific Labrratory Controlled Thermonuclear Energy Research Program Annual Status report, LA-4585-MS (1970), p. 37.

14. A. Haberstich, Los Alamos Scientific Laboratory Controlled Thermonuclear Energy Research Program Annual Status report, LA-5250-PR (1972), p. 54.

15. Smithsonian Physical Tables, 9th edition, (1956) P. 393.

16. J. N. Di Marco and L. C. Burkhardt, Journ. Appl. Phys. 41, 3894 (1970).

17. LASL Controlled Thermonuclear Research Program Progress report, LA-5656-PR, (1973), p. 119.

18. R. A. Haarsan and R. S. Dike, Meeting on Energy Storage, Compressions, and Switching, Torino, Italy, (November 1974), to be published.
19. L. C. Burkhardt, R. S. Dike, J. N. D1 Marco, J. A. Phillips, R. A. Haarman, and A. E. Schofield, "The Magnetic Energy Storage Sygtem Used on ZT-1," ibid.

20. L. A. Artsimovich, S. V. Mirnov, v. S. Strelkov, Atomnaya Energiya 17, 3, 170 (1964).

21. v. S. Mukhovatov, Gulham Meet1ng 2, 577 (1965).

22. Sinclair et el, Phys. Fluids 6, 937 (1963).

23. T. Jernigan and D. Meade, unpublished.

24. D. W. Kerst, A. A. Schupp, H. K. Forsen, J. of Nucl. Energy Pt. C, 5, 161, (1963).

25. Los Alamos Sclentific Laboratory Controlled Thermonuclear Research Program Annual report, December 1973, p. 96.

26. W. Wolman and $H$. Kaden, Zeitschr. für techn. Physik 13, 330 (1932).

27. S. D. Winter, R. W. Kuenning, and G. G. Berg, UCRL preprint UCRL-71514, (1969).

28, R. S. Dike and R. W. Kewish, Jr., "The Development of a High-Explosive Driven Crowbar Switch," Proc. of the Fifth Symposium on Engineering Problems of Fusion Research, Princeton, N. J. (November 1973), IEEE, New York, p. 658. 